\title{
Properties of inertia-gravity waves in the lowermost stratosphere as observed by the PANSY radar over Syowa Station in the Antarctic
}

\author{
Maria Mihalikova ${ }^{1}$, Kaoru Sato $^{1}$, Masaki Tsutsumi ${ }^{2}$, and Toru Sato ${ }^{3}$ \\ ${ }^{1}$ Department of Earth and Planetary Science, The University of Tokyo, Tokyo, Japan \\ ${ }^{2}$ National Institute of Polar Research, Tachikawa, Tokyo, Japan \\ ${ }^{3}$ Department of Communications and Computer Engineering, Kyoto University, Kyoto, Japan \\ Correspondence to: Maria Mihalikova (maja.mihi@gmail.com)
}

Received: 31 October 2015 - Revised: 25 January 2016 - Accepted: 11 April 2016 - Published: 10 May 2016

\begin{abstract}
Inertia-gravity waves (IGWs) are an important component for the dynamics of the middle atmosphere. However, observational studies needed to constrain their forcing are still insufficient especially in the remote areas of the Antarctic region. One year of observational data (January to December 2013) by the PANSY radar of the wind components (vertical resolution of $150 \mathrm{~m}$ and temporal resolution of $30 \mathrm{~min}$ ) are used to derive statistical analysis of the properties of IGWs with short vertical wavelengths ( $\leq 4 \mathrm{~km}$ ) and ground-based periods longer than $4 \mathrm{~h}$ in the lowermost stratosphere (height range 10 to $12 \mathrm{~km}$ ) with the help of the hodograph method. The annual change of the IGWs parameters are inspected but no pronounced year cycle is found. The year is divided into two seasons (summer and winter) based on the most prominent difference in the ratio of Coriolis parameter $(f)$ to intrinsic frequency $(\hat{\omega})$ distribution. Average of $f / \hat{\omega}$ for the winter season is 0.40 and for the summer season 0.45 and the average horizontal wavelengths are 140 and $160 \mathrm{~km}$ respectively. Vertical wavelengths have an average of $1.85 \mathrm{~km}$ through the year. For both seasons the properties of IGWs with upward and downward propagation of the energy are also derived and compared. The percentage of downward propagating waves is 10.7 and $18.4 \%$ in the summer and winter season respectively. This seasonal change is more than the one previously reported in the studies from mid-latitudes and model-based studies. It is in agreement with the findings of past radiosonde data-based studies from the Antarctic region. In addition, using the so-called dualbeam technique, vertical momentum flux and the variance of the horizontal perturbation velocities of IGWs are examined. Tropospheric disturbances of synoptic-scale are suggested as a source of episodes of IGWs with large variance of horizon-
\end{abstract}

tal perturbation velocities, and this is shown in a number of cases.

Keywords. Meteorology and atmospheric dynamics (middle atmosphere dynamics; waves and tides)

\section{Introduction}

Inertia-gravity waves (IGWs), i.e. waves for which the restoring force is buoyancy, are ubiquitous in the atmosphere and generally are small scale. The importance of their contribution in driving the dynamics of the middle atmosphere has been recognised for a long time. IGWs propagate vertically into the stratosphere and mesosphere, where their saturation and/or dissipation alters not only the local wind but also induces meridional circulation at these altitudes (e.g., Fritts and Alexander, 2003). Small-scale gravity waves are not resolved by common global circulation models and their forcing is included into the models through parameterisations with different assumptions and tunings according to the goals of the respective model (Alexander et al., 2010). One major problem also discussed by McLandress et al. (2012) is the missing $\mathrm{GW}$ drag around $60^{\circ} \mathrm{S}$ in nearly all chemistry-climate models, which introduces the so called cold-pole bias (too cold and too strong polar vortex with later break-down) in the models and therefore having an influence on the prediction of the ozone-hole dissipation timing. For better understanding of IGW characteristics and for the improvement of the physical constrains of model parameterisations further observational studies in the southern polar stratosphere are very important. There are studies in the low and midlatitudes examining in detail the properties of gravity waves using high- 
resolution radar data, which provide a good basis for a statistical overview of properties of IGWs in the lower stratosphere in the midlatitudes (see e.g. Sato, 1994). This study used the hodograph method to extract properties of IGWs between 16 and $22 \mathrm{~km}$ from the routine wind observation by the MU radar in Shigaraki, Japan. They found an annual cycle with a maximum in winter in the seasonal variation of IGWs intensity. Two seasons (winter and summer) with strong and weak subtropical jets were examined and strong anisotropy in horizontal energy propagation direction was observed. In the vertical direction, more than $90 \%$ of IGWs propagate energy upward. Horizontal wavelengths were between 200 and $500 \mathrm{~km}$, vertical wavelengths about $2 \mathrm{~km}$, shorter in summer, $f / \hat{\omega}$ was on average 0.5 , larger in the summer and the degree of saturation was found larger in winter than in summer. More recent midlatitude study by Vaughan and Worthington (2007) shows an analysis of 8 years of observations from UK MST radar at Aberyswyth, Wales. They found typical vertical wavelengths of $2 \mathrm{~km}$ and amplitudes of $1-3 \mathrm{~m} \mathrm{~s}^{-1}$ and long horizontal wavelengths of around $500 \mathrm{~km}$. Long-period waves $(>12 \mathrm{~h}$ ) were observed $70 \%$ of the time in the lower stratosphere with little seasonal dependence. Shorter wavelengths $(6-8 \mathrm{~h})$ were observed $10-30 \%$ of the time in the troposphere and stratosphere with a winter maximum in the occurrence rate. They found only weak correlation with the jet stream. A different study from the same radar site performed by Chagnon and Gray (2008) utilises wavelet analysis and modelling to examine an episode of vertically propagating high-frequency waves in the lower stratosphere generated by deep convection which reached the troposphere. Other midlatitude studies use radiosonde data, e.g. Allen and Vincent (1995) who examined latitudinal and seasonal variation of gravity wave spectra. However, in the remote Antarctic areas, where the collection of data is complicated because of the severe natural environment, the properties and sources of IGWs and their climatology are still not sufficiently understood. Nevertheless, observational studies are gradually being made for various areas of the southern polar region using all available past and new data. Using operational radiosonde data from 33 stations over a period of 10 years in the Arctic and Antarctic, Yoshiki and Sato (2000) looked at the comparison of gravity wave properties in the lower polar stratosphere between the hemispheres and their climatologies. They showed that the potential and kinetic energies of gravity waves in the height region $15-20 \mathrm{~km}$ are maximised in the spring in the Antarctic and in the winter in the Arctic. In the Arctic region, gravity waves mostly transport energy upwards with westward dominant horizontal propagation direction relative to the mean wind. There is a higher percentage of downward energy propagating waves in the winter and spring in the Antarctic and dominant direction of horizontal propagation varies depending on the station. They suggested that the polar night jet could be a possible source of the downward energy propagating gravity waves in the Antarctic. Yoshiki et al. (2004) analysed 2 years of op- erational radiosonde data with fine vertical resolution from Syowa Station $\left(69.0^{\circ} \mathrm{S}, 39.6^{\circ} \mathrm{E}\right)$. They showed that the temporal variation in gravity wave energy depends on height and in the region of $13-15 \mathrm{~km}$ its seasonal variation is not evident. They suggested that tropospheric disturbances affect the dynamical processes of gravity waves in this lowest region of the stratosphere. Intensive radiosonde observations in all seasons of 1 year over Syowa Station were performed by Sato and Yoshiki (2008) to analyse seasonal variation of gravity wave properties. Dynamical characteristics were also examined separately for simultaneous upward- and downward-propagating waves and were found to have similar horizontal wavelengths and phase velocities which suggest a common source in the lower stratosphere for both of the groups. Model simulations and comparison with measures of imbalance (local Rossby numbers and residual in the nonlinear balance equation) suggested the polar night jet as a probable source of these waves. The Antarctic peninsula and the southern Andes are long recognised as strong sources of gravity waves and wave properties were examined using a variety of instruments (see e.g., McLandress et al., 2000; Wu, 2002, 2004; Jiang, 2002; Hertzog et al., 2008). Recently, a study was made based on radiosondes by Moffat-Griffin et al. (2011) using the observations from Rothera $\left(67.6^{\circ} \mathrm{S}\right.$, $68.1^{\circ} \mathrm{W}$ ) which found a peak of lower stratospheric wave energy densities at equinoxes and enhanced level of downward propagation in the wintertime. A similar study performed at the Falkland Islands found different energy density variations but similar percentages of downward propagating waves (Moffat-Griffin et al., 2013). Murphy et al. (2014) performed a wavelet analysis of 12 years of radiosonde observations at Davis station $\left(68.6^{\circ} \mathrm{S}, 78^{\circ} \mathrm{E}\right)$ and compiled a climatology of lower stratosphere IGWs characteristics. In the statistics the vertical propagation shows strong height and temporal variations. Waves propagate nearly horizontal and are strongly advected by the background wind in wintertime. A significant percentage of waves observed in the stratosphere during wintertime propagates downward. They conclude based on the similarity of downward and upward propagating waves and the vertical structure of the nonlinear balance residual that a source due to imbalanced flow, distributed over the winter lower stratosphere is a suitable explanation for the observations. Properties of IGWs were also intensively investigated by using gravity-wave resolving models and compared to observations and models which do not resolve IGWs but include their influence through parameterisations (see e.g., Sato et al., 2009, 2012; Geller et al., 2013). These studies find the importance of latitudinal propagation of IGWs in the high latitudes of the winter hemisphere from their sources in the troposphere or lower stratosphere towards the axis of mesospheric jets (around $60^{\circ} \mathrm{S}$ ). Such propagation characteristics of waves determine the latitudinal distribution of momentum flux (Sato et al., 2009). Sato et al. (2012) also illustrates that orographic gravity waves can propagate significantly leeward by the mean wind component perpendic- 
ular to the wavenumber vector. These properties of gravity waves are not yet properly constrained in parametrisation of climate and general circulation models which causes differences in model outputs of absolute momentum fluxes in high latitudes of the winter hemisphere from observations and gravity-wave resolving models as discussed by Geller et al. (2013). Observation by the PANSY radar can help to determine the sources of gravity waves which is necessary for further constraining of model parametrisation. Recently a study by Shibuya et al. (2015) used both the PANSY radar observations and model simulations to explain three cases of occurrence of multiple tropopauses observed over Syowa Station. They also discussed the possible role of IGWs appearing in association with the multiple tropopause folding events and the relative importance of orographically and nonorographically produced gravity waves around $60^{\circ} \mathrm{S}$ and conclude that nonorographically generated gravity waves can play an important part in the momentum flux. In the present study, to further improve our understanding of IGWs in the southern polar lower stratosphere, we used a year of continuous measurements by PANSY radar at the Syowa Station (described in Sect. 2.1). After extracting the perturbation velocities of IGWs (Sect. 2.2) we obtained properties of IGWs using the hodograph method (Sect. 2.3) and a statistical overview of gravity wave properties and their seasonal changes was made (Sect. 3). We also explore the possible sources of strong wave activity episodes observed by PANSY radar and discuss these in Sect. 4.

\section{Data and methodology}

\subsection{Data}

The PANSY radar is a Mesosphere-StratosphereTroposphere/Incoherent Scatter (MST/IS) radar installed at Syowa Station $\left(69.0^{\circ} \mathrm{S}, 39.6^{\circ} \mathrm{E}\right)$ in the Antarctic region. Details of the PANSY program are given by Sato et al. (2014). The PANSY radar provides high-resolution vertical profiles of wind vectors including their vertical components with high accuracy at time intervals of about $1 \mathrm{~min}$. A partial system of the radar has been in operation since May 2012. For the analysis presented in this study, data obtained by routine wind observation by the PANSY radar from January 2013 until December 2013 were used. Incoherent-integrated data with temporal resolution of $30 \mathrm{~min}$ gained by five beams, one directed vertically and other four tilted to the north, east, south and west under the zenith angle of $10^{\circ}$ were utilised to calculate the vertical, zonal and meridional wind speeds with the vertical resolution of $150 \mathrm{~m}$ along the beam directions. An example of a typical measurement of zonal and meridional wind speeds by the PANSY radar is shown in Fig. 1. The figure shows a case of stronger wave activity over Syowa Station at the end of June 2013 and beginning of July 2013. Wave-like structures can be observed in the meridional and zonal wind components.
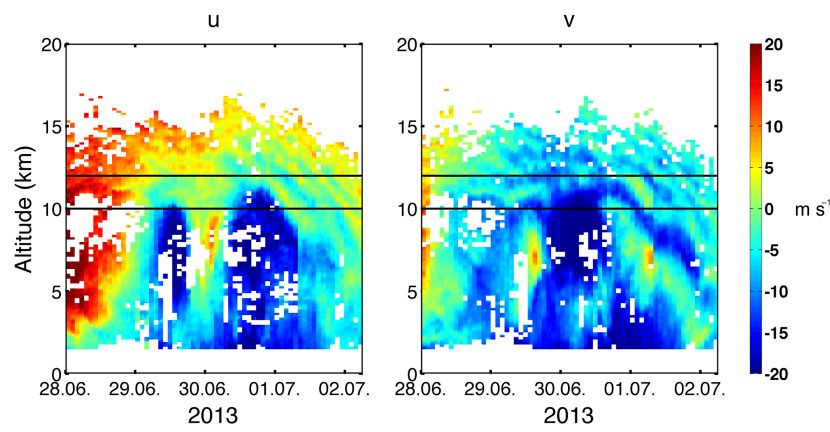

Figure 1. Example of zonal $(u)$ and meridional $(v)$ wind speed measurements of PANSY radar between 28 June and 2 July 2013. (a)

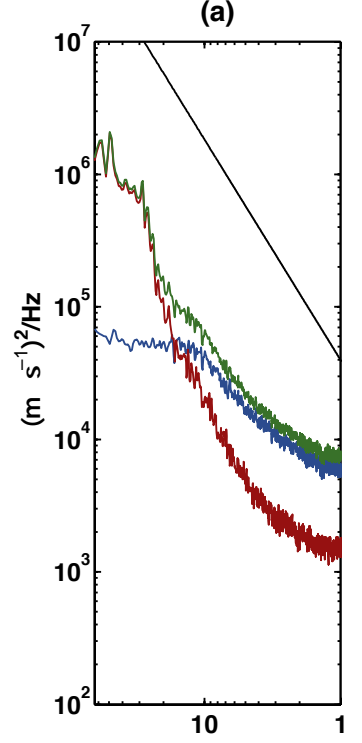

(b)

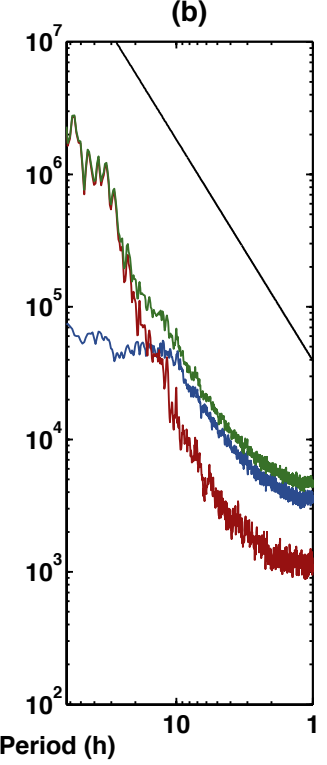

Period (h)

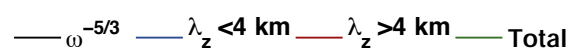

Figure 2. Power spectra of the zonal (a) and meridional (b) wind fluctuations obtained using Blackman-Tukey algorithm between 10 and $12 \mathrm{~km}$ for the year 2013. The blue (red) line shows the spectra for wind fluctuations with the vertical wavelengths shorter (longer) than $4 \mathrm{~km}$ and the green line shows the spectra for all components.

Considering the quality and availability of data in the year 2013 this study decided to concentrate on the analysis of the height region 10 to $12 \mathrm{~km}$ (denoted by horizontal black lines in Fig. 1). It is the lowermost region of the stratosphere just above the tropopause and thus represents the entrance zone of IGWs with tropospheric sources into the stratosphere. Data from JMA operational radiosonde observations were utilised for the calculation of buoyancy frequency values in the analysed heights. ECMWF ERA-Interim reanalysis data of geopotential height, wind speeds and relative vorticity was used for additional analysis. 

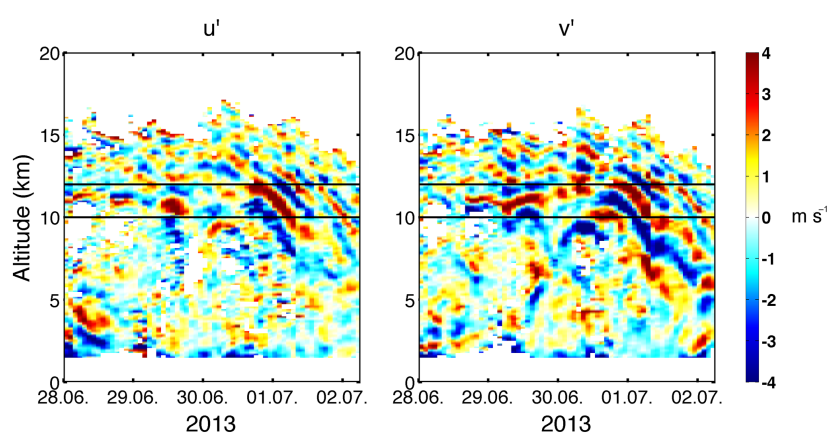

Figure 3. Example of zonal $\left(u^{\prime}\right)$ and meridional $\left(v^{\prime}\right)$ horizontal wind perturbations extracted with cutoff vertical wavelength $4 \mathrm{~km}$ and cutoff period $4 \mathrm{~h}$ between 28 June and 2 July 2013.

\subsection{Definition and extraction of IGWs perturbation velocities}

Analysis presented here was performed similarly to the study by Sato (1994). The data were at first screened for erroneous data-points and then a high-pass filter with a cutoff vertical wavelength of $4 \mathrm{~km}$ was used to extract the horizontal wind wave components in the height direction. A cutoff wavelength of $4 \mathrm{~km}$ was decided upon based on the examination of the data and previous radiosonde studies in the area of Syowa Station (e.g., Sato and Yoshiki, 2008). To obtain the cutoff period of IGWs, frequency power spectra of zonal and meridional wind fluctuations in the height region of $10-12 \mathrm{~km}$ were obtained using Blackman-Tukey algorithm and are shown in Fig. 2. The blue (red) line shows the spectra for wind fluctuations with the vertical wavelengths shorter (longer) than $4 \mathrm{~km}$ and the green line showing the spectra for all components. The spectral density is larger for shorter wavelengths in a range shorter than 10-13 $\mathrm{h}$. Taking a broad bandwidth the cutoff period of the lowpass filter to extract the IGWs at the Syowa Station was estimated to be $4 \mathrm{~h}$. Thus, IGW components $\left(u^{\prime}, v^{\prime}, w^{\prime}\right)$ are here defined as fluctuations with the vertical wavelength $\lambda_{z}<4 \mathrm{~km}$ and the period $\tau>4 \mathrm{~h}$. Figure 3 shows an example of the extracted horizontal perturbation wind velocities for the same time period as shown in Fig. 1.

\subsection{Method used to gain characteristics of IGWs}

For extraction of IGW parameters, we used the hodograph method following Sato (1994). The method of least squares was used to fit an ellipse to each $30 \mathrm{~min}$ vertical profile between 10 and $12 \mathrm{~km}$ divided into two height intervals (i.e. 1011.5 and $10.5-12 \mathrm{~km}$ ), each consisting of 11 points (representing $1.5 \mathrm{~km}$ ) and overlapping by 5 points. Although waves with different properties can be observed at the same time in the same heights monochromaticity was assumed since a relatively small vertical range was used for the fitting. Fitting was performed with fixed $\lambda_{z}$ with a $0.1 \mathrm{~km}$ step between 0.5 and $4.5 \mathrm{~km}$. This enables a stable fitting process. The optimal parameters with least residuals for the combination of meridional and zonal components were obtained whenever the observations were available with sufficient echo power and further properties of IGWs were derived based on the properties of the fitted ellipse. The wavelength gained from the fitting process to the horizontal perturbation velocities was further used to derive fit parameters for the vertical component. Perturbation velocities of IGWs calculated as a result of the fitting process are, if needed, further denoted as $u_{\mathrm{f}}^{\prime}, v_{\mathrm{f}}^{\prime}, w_{\mathrm{f}}^{\prime}$. The dispersion and polarisation relations for IGWs were used to derive the values of intrinsic frequency $\hat{\omega}$ and horizontal wavelength $\lambda_{\mathrm{h}}$. The effect of background wind shear perpendicular to the horizontal wavenumber vector was considered to be negligible and not considered in further calculations. The polarisation relation gives for the ratio of the short $(b)$ to long axis $(a)$, the following relation:

$\frac{b}{a}=\left|\frac{f}{\hat{\omega}}\right|$,

where $f$ is the Coriolis parameter at Syowa Station $\left(-1.358 \times 10^{-4} \mathrm{~s}^{-1}\right)$ and $\hat{\omega}$ is intrinsic frequency. Furthermore the horizontal wavenumber vector $\boldsymbol{k}_{\mathrm{h}}$ of the IGWs can be gained from the dispersion relation:

$\frac{\boldsymbol{k}_{\mathrm{h}}^{2}}{m^{2}}=\frac{\hat{\omega}^{2}-f^{2}}{N^{2}}$,

where $N$ is Brunt-Väisälä frequency and $m$ is the vertical wavenumber. The values of $N$ used for the calculations were derived as time averages over the analysed height range from the operational JMA radiosonde data. Vertical energy propagation direction can be determined from the direction of rotation of the hodograph with the altitude. In the Southern Hemisphere, the anticlockwise (clockwise) rotation with the altitude shows upward (downward) energy propagation. Horizontal IGWs' propagation direction $(\Phi)$ is the same as the direction of the horizontal wavenumber vector. The horizontal wavenumber vector is parallel to the long axis of the ellipse with an ambiguity of $180^{\circ}$. This ambiguity can be removed by phase difference between the vertical perturbation velocity and the horizontal perturbation velocity parallel to the long axis using the theoretical property of IGWs that for the upward (downward) energy propagating waves $m<0(m>0)$, the perturbation velocities are in phase (out of phase). Ground-based frequency $\omega_{\text {obs }}$ is related to the intrinsic frequency

$\omega_{\mathrm{obs}}=\hat{\omega}+|\boldsymbol{U}||\boldsymbol{k}| \cos \left(\Phi_{\mathrm{W}}-\Phi\right)$,

where $\Phi_{\mathrm{W}}$ is the horizontal wind direction. Another property, the degree of saturation $S$ can be derived by comparing the horizontal perturbation wind speed parallel to the horizontal wavenumber $\left|u_{\mathrm{p}}^{\prime}\right|$ and the intrinsic phase velocity $\left|C_{\mathrm{int}}\right|$,

$S=\frac{\left|u_{\mathrm{p}}^{\prime}\right|}{\left|C_{\mathrm{int}}\right|}$ 
This relation was considered by Lindzen (1981) who explained that breaking of the gravity wave by convective instability occurs when $\left|u_{\mathrm{p}}^{\prime}\right|$ becomes larger than the intrinsic phase velocity $\left|C_{\text {int }}\right|$. Thus the wave with an amplitude $\left|u_{\mathrm{p}}^{\prime}\right|=\left|C_{\text {int }}\right|$ is called a saturated gravity wave. A spectral model of saturated gravity waves was proposed by Smith et al. (1987) and based on good agreements between the theory and observations it became widely accepted. Sato (1994) used this relation for statistical examination of the saturation of monochromatic IGWs using parameters obtained by hodograph analysis in the lower stratosphere. Additionally, using the continuity equation under Boussinesq approximation, the horizontal wavelengths can be estimated from the ratio of vertical and horizontal perturbation amplitudes,

$\boldsymbol{k}_{\mathrm{h}} u_{\mathrm{p}}^{\prime}+m w^{\prime}=0$.

This estimation is independent of the one using Eqs. (1) and (2), which makes the validation of the obtained wave parameters possible. During the analysis several conditions for validity of fitting were applied. Fits that did not comply with them were rejected. The ratio of variance of the fitted horizontal perturbations to their residuals had to be larger than or equal to 0.75 . The horizontal perturbation velocity in the direction of the long axis had to exceed $0.7 \mathrm{~m} \mathrm{~s}^{-1}$. Linearly and circularly polarised waves were also excluded (the ratio of long and short axis had to be greater than 0.1 and smaller than 0.9).

\section{Results}

As the analysed height range is only $2 \mathrm{~km}$, all the properties were considered to represent one height only and change of the properties with the height was not investigated. Hodograph analysis as described in Sect. 2.3 was used to derive intrinsic frequency $\hat{\omega}$, vertical wavelength $\lambda_{z}$, horizontal wavelength $\lambda_{\mathrm{h}}$, vertical and horizontal propagation direction and the degree of saturation $S$. At first all the properties of IGWs were summarised according to months to search for the possible seasonal variability. A well-defined year cycle of IGW properties was not found unlike those in the mid-latitudes (Sato, 1994). The only property that showed some clear variability in our case was the mean intrinsic frequency, here represented by the ratio of the Coriolis parameter and intrinsic frequency $f / \hat{\omega}$. Its mean monthly values, shown in Fig. 4, are between 0.38 and 0.48 , lower during the winter months. This shows that there is a prevalence of IGWs with higher $\hat{\omega}$ during the winter months. The mean $f / \hat{\omega}$ for July of 0.42 (horizontal line in Fig. 4) was chosen to divide the year into two seasons: the winter season, covering the months April to November 2013 and the summer season consisting of January to March and December 2013. Further the properties of the IGWs were analysed based on this grouping.

A histogram of the ratio $f / \hat{\omega}$ can be seen in Fig. 5a for the summer with a slight maximum around the average of

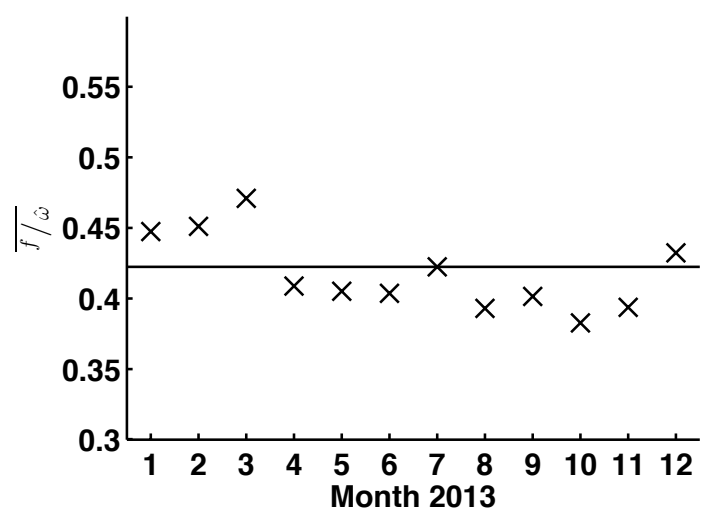

Figure 4. Mean monthly values of $f / \hat{\omega}$ for year 2013
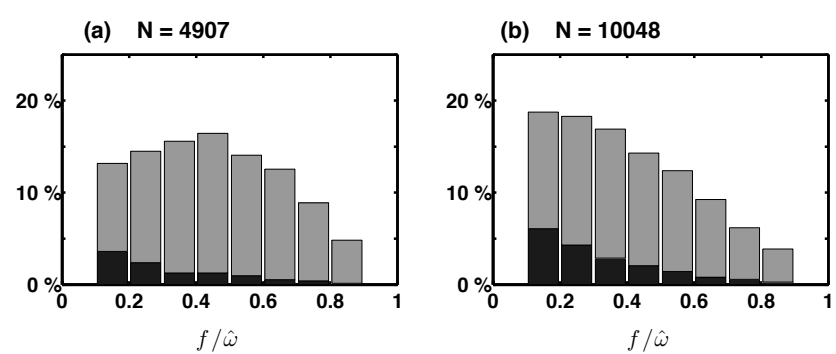

Figure 5. Histogram of the parameter $f / \hat{\omega}$ for summer (a) and winter (b) season. Grey and black parts of the histogram represent the upward and downward energy propagating IGWs respectively.

0.45 and decreasing in the higher values. In the winter season (Fig. 5b) we see a steady decrease of the $f / \hat{\omega}$ from the maximum found at 0.15 with the average value of 0.40 . The black coloured part of the histogram in Fig. 5 represents the histogram for downward energy propagating waves. In both cases downward propagating waves have on average higher intrinsic frequencies with mean $f / \hat{\omega}$ being 0.32 . In this and all consequent figures the number $N$ represents number of observations included in the statistics. Throughout the whole year, $16 \%$ of the IGWs were found to be propagating energy downward. This percentage is higher in the winter season being $18.5 \%$ and lower during the summer season being $10.7 \%$. These numbers are consistent with other studies made for the southern polar latitudes (eg. Yoshiki and Sato, 2000; Moffat-Griffin et al., 2011; Murphy et al., 2014) and show a higher ratio of downward propagating waves existing in high latitudes as opposed to up to maximum $10 \%$ in mid-latitudes (Sato, 1994). The dominant horizontal propagation direction exhibited random variability during the year and, depending on the month and on the average it does not show much difference between the winter and summer season. In both cases the northward propagating IGWs are slightly dominant. In Fig. 6 the horizontal propagation directions with their percentages for summer and winter season and for upward energy propagating waves (Fig. 6a and b respectively) and downward energy propagat- 
(a) $\mathrm{N}=4383$

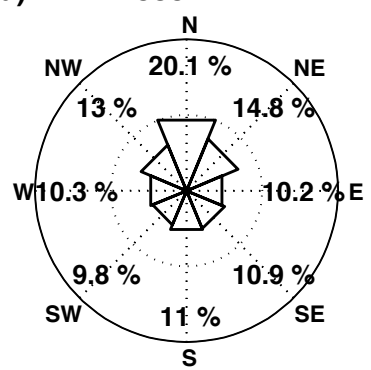

(c) $\mathrm{N}=524$

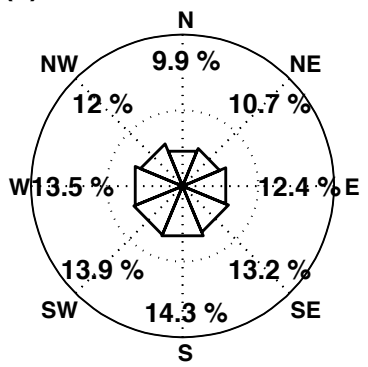

(b) $\mathrm{N}=8201$

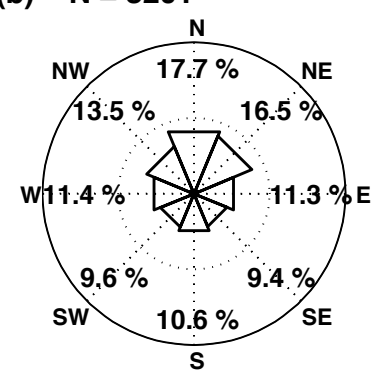

(d) $\quad \mathrm{N}=1847$

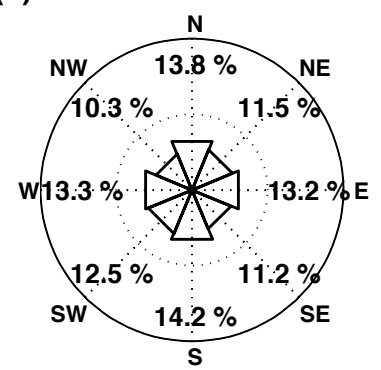

Figure 6. Horizontal propagation directions of IGWs for summer and winter season of upward energy propagating waves (a) and (b) respectively and downward energy propagating waves (c) and (d) respectively.

(a) $\mathrm{N}=4907$

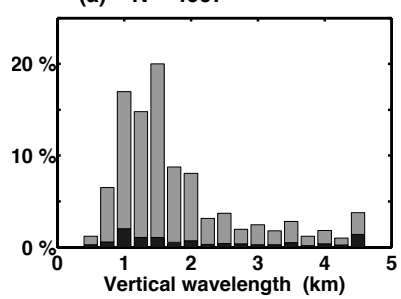

(b) $\mathrm{N}=10048$

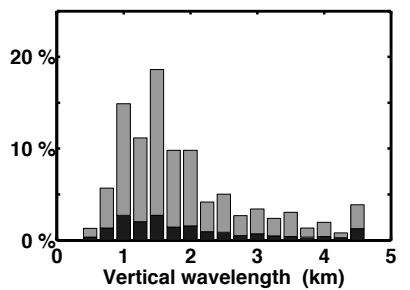

Figure 7. Distribution of vertical wavelengths for summer (a) and winter (b) season. Grey and black parts of the histogram represent the upward and downward energy propagating IGWs respectively.

ing waves (Fig. 6c and d respectively) are shown. In both seasons upward energy propagating waves have dominant northward and northeastward propagation direction. On the other hand downward propagating waves have slightly dominant southward to westward propagation directions. Vertical wavelength (Fig. 7) shows only minimal variation during the year with an average of $1.85 \mathrm{~km}$ and similar distribution for upward and downward propagating waves, although winter season distribution (Fig. 7b) shows a higher ratio of longer $\lambda_{z}$.

Average horizontal wavelength in the summer season (Fig. 8a) was found to be $160 \mathrm{~km}$ with standard deviation of $125 \mathrm{~km}$ and in the winter season (Fig. 8b) $139 \pm 120 \mathrm{~km}$. In both cases, the group of downward propagating waves show shorter averages of the horizontal wavelength of $140 \mathrm{~km}$ in

(a) $\mathrm{N}=4907$

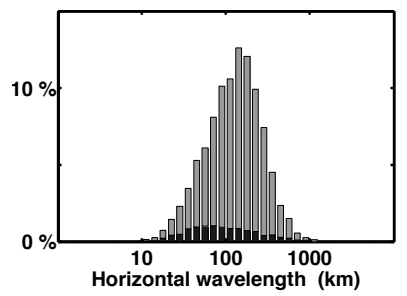

(b) $\quad \mathrm{N}=10048$

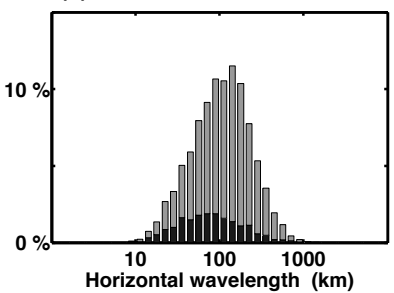

Figure 8. Distribution of horizontal wavelength for summer (a) and winter (b) season. Grey and black parts of the histogram represent the upward and downward energy propagating IGWs respectively.
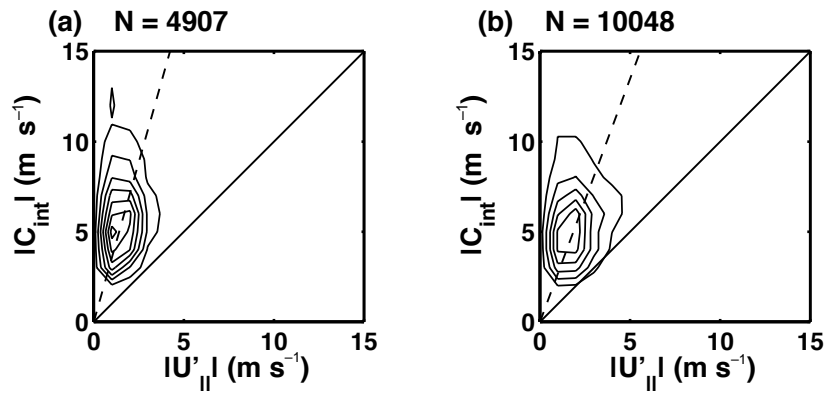

Figure 9. Distribution of intrinsic phase velocity $\left(C_{\text {int }}\right)$ and perturbation velocity parallel to the horizontal wavenumber vector $\left(U_{\|}^{\prime}\right)$ of IGWs for summer (a) and winter (b). The step of lines is 1 and the unit is arbitrary.

the summer season and $114 \mathrm{~km}$ in the winter season. This might be a sign of a different source of downward propagating and upward propagating waves in this region.

The degree of saturation $S$, i.e., the normalised distribution of the perturbation wind speed parallel to the horizontal wavenumber vector $\left|u_{\mathrm{p}}^{\prime}\right|$ and intrinsic phase velocity $\left|C_{\mathrm{int}}\right|$ (Eq. 4), is shown in Fig. 9. $S$ for a monochromatic saturated wave becomes equal to one (diagonal black line in Fig. 9). The average degree of saturation for the whole year is 0.37 , being for the summer 0.32 and for the winter 0.41 . The IGWs interact with background wind slightly more effectively during the winter season as can also be seen on the difference in the shape of the distributions for summer (Fig. 9a) and winter (Fig. 9b). Properties of IGWs for individual seasons are summarised in the first part of Table 1. It can be seen that the average vertical wavelengths are similar for both seasons but horizontal wavelengths are on average $20 \mathrm{~km}$ longer in the summer season. This reflects also on the higher value of the $f / \hat{\omega}$ parameter. Dominant horizontal propagation directions in both seasons are northward and northeastward but only slightly more with $33 \%$. The downward energy propagating waves are more dominant in the winter season with $18.4 \%$ in contrast to $10.7 \%$ in the summer season. In addition to the statistical overview of the properties of IGWs, monthly means of vertical momentum flux components between 10 and $12 \mathrm{~km}$ were calculated according to the so-called dual- 
Table 1. Overview of mean properties of IGWs for different seasons and studied cases of strong wave activity. DP stands for Downward Propagating and UP for Upward Propagating.

\begin{tabular}{|c|c|c|c|c|c|c|c|c|c|c|c|}
\hline \multicolumn{2}{|c|}{ Time period } & \multicolumn{2}{|c|}{$\lambda_{z}(\mathrm{~km})$} & \multicolumn{2}{|c|}{$\lambda_{\mathrm{h}}(\mathrm{km})$} & \multicolumn{2}{|c|}{$f / \hat{\omega}$} & \multicolumn{2}{|c|}{ Propagation direction } & \multirow{2}{*}{$\begin{array}{c}\text { DP } \\
10.7 \%\end{array}$} & \multirow{2}{*}{$\begin{array}{r}S \\
0.32\end{array}$} \\
\hline Summer & $\begin{array}{l}\text { UP } \\
\text { DP }\end{array}$ & $1.8 \pm 0.96$ & $\begin{array}{c}1.75 \\
2.2\end{array}$ & $160 \pm 130$ & $\begin{array}{l}160 \\
140\end{array}$ & 0.45 & $\begin{array}{l}0.47 \\
0.32\end{array}$ & N-NE $(33.3 \%)$ & $\begin{array}{l}\text { N-NE }(35 \%) \\
\text { S-W }(42 \%)\end{array}$ & & \\
\hline Winter & $\begin{array}{l}\text { UP } \\
\text { DP }\end{array}$ & $1.9 \pm 0.96$ & $\begin{array}{l}1.9 \\
2.0\end{array}$ & $140 \pm 120$ & $\begin{array}{l}145 \\
115\end{array}$ & 0.40 & $\begin{array}{l}0.42 \\
0.31\end{array}$ & N-NE $(32.6 \%)$ & $\begin{array}{l}\text { N-NE }(34 \%) \\
\text { S-W }(40 \%)\end{array}$ & $18.4 \%$ & 0.41 \\
\hline \multicolumn{2}{|c|}{$\begin{array}{r}\text { Case A }-2013 / 01 / 2412: 00 \text { UTC } \\
-2013 / 01 / 27 \text { 06:00 UTC }\end{array}$} & \multicolumn{2}{|c|}{$2.3 \pm 0.99$} & \multicolumn{2}{|c|}{$255 \pm 195$} & \multicolumn{2}{|c|}{0.52} & \multicolumn{2}{|c|}{ SE-S $(52.2 \%)$} & $6.7 \%$ & 0.48 \\
\hline \multicolumn{2}{|c|}{$\begin{aligned} \text { Case B } & -2013 / 04 / 17 \text { 06:00 UTC } \\
& -2013 / 04 / 20 \text { 00:00 UTC }\end{aligned}$} & \multicolumn{2}{|c|}{$1.9 \pm 0.96$} & \multicolumn{2}{|c|}{$190 \pm 140$} & \multicolumn{2}{|c|}{0.50} & \multicolumn{2}{|c|}{ NE-N $(60.5 \%)$} & $1.6 \%$ & 0.50 \\
\hline \multicolumn{2}{|c|}{$\begin{aligned} \text { Case C } & -2013 / 06 / 1906: 00 \text { UTC } \\
& -2013 / 06 / 22 \text { 18:00 UTC }\end{aligned}$} & \multicolumn{2}{|c|}{$2.4 \pm 0.92$} & \multicolumn{2}{|c|}{$190 \pm 140$} & \multicolumn{2}{|c|}{0.43} & \multicolumn{2}{|c|}{$\mathrm{S}(20.5 \%) \mathrm{N}(18.2 \%)$} & $4.9 \%$ & 0.48 \\
\hline \multicolumn{2}{|c|}{$\begin{array}{r}\text { Case D - 2013/06/28 06:00 UTC } \\
-2013 / 07 / 02 \text { 00:00 UTC }\end{array}$} & \multicolumn{2}{|c|}{$2.0 \pm 0.80$} & \multicolumn{2}{|c|}{$180 \pm 110$} & \multicolumn{2}{|c|}{0.50} & \multicolumn{2}{|c|}{$\mathrm{N}-\mathrm{NE}(55.3 \%)$} & $1.0 \%$ & 0.51 \\
\hline \multicolumn{2}{|c|}{$\begin{array}{r}\text { Case E - 2013/09/17 00:00 UTC } \\
-2013 / 09 / 18 \text { 06:00 UTC }\end{array}$} & \multicolumn{2}{|c|}{$2.8 \pm 0.99$} & \multicolumn{2}{|c|}{$195 \pm 115$} & \multicolumn{2}{|c|}{0.42} & \multicolumn{2}{|c|}{$\mathrm{N}(40 \%)$} & $1.0 \%$ & 0.40 \\
\hline \multicolumn{2}{|c|}{$\begin{array}{r}\text { Case F - 2013/11/21 12:00 UTC } \\
-2013 / 11 / 26 \text { 00:00 UTC }\end{array}$} & \multicolumn{2}{|c|}{$2.4 \pm 0.95$} & \multicolumn{2}{|c|}{$230 \pm 200$} & \multicolumn{2}{|c|}{0.44} & \multicolumn{2}{|c|}{$\operatorname{NE}(28.9 \%)$} & $8.0 \%$ & 0.52 \\
\hline
\end{tabular}

beam technique described by Vincent and Reid (1983). Under the assumption of homogenous horizontal atmospheric motions, this method provides accurate estimates for MST radar observations with a five beam configuration as in the case of the PANSY radar. In this case filtered line-of-sight wind fluctuation components (cutoff wavelength $\lambda_{z}<4 \mathrm{~km}$ and the cutoff period $\tau>4 \mathrm{~h}$ ) were used for the calculations and the results are shown in Fig. 10. The vertical flux of meridional momentum $\overline{v^{\prime} w^{\prime}}$ is close to zero or slightly positive throughout the year with higher values in October and November 2013. Monthly means of the vertical flux of zonal momentum $\overline{u^{\prime} w^{\prime}}$ show a change through the year with negative values from January to July 2013 and positive values from August to December 2013. Considering the lower altitude (higher air pressure) of the examined region, the levels of momentum flux are higher than those found in midlatitudes by Sato (1994). In the variance of horizontal perturbation velocities $\overline{u^{\prime 2}+v^{\prime 2}}$ (third panel of Fig. 10), which represents the wave activity in the given month, higher values can be seen from April to August 2013 and then a well-defined peak in the November 2013. Monthly means of the background wind speed (fifth panel of Fig. 10) in the analysed region changed between 5 and $20 \mathrm{~m} \mathrm{~s}^{-1}$.

\section{Sources of strong wave activity episodes}

Proximity of jet streams, as one potential source of gravity waves, to Syowa Station through the year was examined using the ERA Interim data (not shown here). The axis of tropospheric jet stream was always found to be north of Syowa Station around $50-60^{\circ} \mathrm{S}$. Since the majority of IGWs observed at Syowa during the whole year were found to horizontally propagate northwestward to northeastward (45.8\%), geostrophic adjustment at the axis of the jet could be a source of only part of the observed IGWs. After examining $\overline{u^{\prime 2}+v^{\prime 2}}$ in more detail, it was found that the pronounced peak in November 2013 is a result of a few strong wave activity periods. Stronger wave activity periods on the scale of several days can be seen in PANSY data through the year. The lower panel of Fig. 11 shows the variance of horizontal perturbation velocities with the time. These values were derived as $6 \mathrm{~h}$ averages of $\overline{u^{\prime 2}+v^{\prime 2}}$ to match the time resolution of ERA Interim data and smoothed out by using a running mean of roughly 1 day. Clear periods of stronger wave activity on the scale of one to 6 days are seen through the year. Looking through the properties of a few random cases and the synoptical situation at the given times, it was concluded that they might be connected to synoptic-scale activity around Syowa Station. In the upper panel of Fig. 11, we can see the time dependence of the average of squared relative vorticity, derived from ERA Interim data, (as measure of synoptic scale activity) in an area around Syowa Station at $300 \mathrm{hPa}$ level. This is just underneath the explored height range. Six cases of strong wave activity were chosen and studied in more detail. For the chosen cases, the maximum $\overline{u^{\prime 2}+v^{\prime 2}}$ was greater than $10 \mathrm{~m}^{2} \mathrm{~s}^{-2}$ and the coverage of the period by successful fits was greater than $70 \%$. The length of the period was decided as the times around the peaks when $\overline{u^{\prime 2}+v^{\prime 2}}$ was greater than 1.25 times the year mean value of $\overline{u^{\prime 2}+v^{\prime 2}}$. The chosen case periods are shown in Fig. 11 letters A - F in red. Example of PANSY measurements and the extracted perturbation velocities during one of our cases (Case D) can be seen in Figs. 1 and 3. As can be seen in Fig. 11 few cases with large variance were omitted from the analysis. These were the cases when the coverage by the measurements and fits was less than $70 \%$ of the time period. 
Table 2. Overview of mean properties of IGWs for different seasons and studied cases of strong wave activity. $\tau$ is observed period and $C_{v}$ observed phase speed.

\begin{tabular}{ccccc}
\hline Time period & $\left|\frac{w_{\mathrm{f}}^{\prime}}{u_{\mathrm{p}}^{\prime}}\right|$ & $\left|\frac{\boldsymbol{k}_{\mathrm{h}}}{m}\right|$ & $\tau(\mathrm{h})$ & $C_{v}\left(\mathrm{~m} \mathrm{~s}^{-1}\right)$ \\
\hline Summer & 0.0166 & 0.0165 & $11 \mp 16$ & $6.2 \mp 8.8$ \\
\hline Winter & 0.0172 & 0.0208 & $9 \mp 15$ & $6.2 \mp 10.4$ \\
\hline Case A - 2013/01/24 12:00 UTC & 0.0164 & 0.0132 & $18 \mp 24$ & $8.2 \mp 7.9$ \\
$-2013 / 01 / 2706: 00$ UTC & & & & \\
Case B - 2013/04/17 06:00 UTC & 0.0145 & 0.0145 & $11 \mp 13$ & $5.4 \mp 8.3$ \\
$-2013 / 04 / 2000: 00$ UTC & & & & \\
Case C - 2013/06/19 06:00 UTC & 0.0133 & 0.0183 & $10 \mp 13$ & $7.8 \mp 10.7$ \\
$\begin{array}{r}-2013 / 06 / 22 ~ 18: 00 \text { UTC } \\
\text { Case D - 2013/06/28 06:00 UTC }\end{array}$ & 0.0141 & 0.0153 & $14 \mp 17$ & $5.1 \mp 8.8$ \\
$-2013 / 07 / 0200: 00$ UTC & & & & \\
Case E - 2013/09/17 00:00 UTC & 0.0160 & 0.0183 & $11 \mp 13$ & $5.7 \mp 10.5$ \\
$-2013 / 09 / 1806: 00$ UTC & & & $15 \mp 21$ & $6.4 \mp 10.9$ \\
Case F- 2013/11/21 12:00 UTC & 0.0222 & 0.0164 & 15 UC \\
$-2013 / 11 / 2600: 00$ UTC & & & & \\
\hline
\end{tabular}

The synoptic situation during these periods was examined in greater detail using the ERA Interim data. Common properties were found for all of the six cases. Maps of the geopotential height and wind speed at $300 \mathrm{hPa}$ level around the time of the maximum variance of the horizontal perturbations of each respective case are shown in Fig. 12. In all cases, a lowpressure area is seen to the north or northwest of Syowa Station. Thus Syowa Station is placed in the front or higher latitude part of the low-pressure system. These low-pressure systems are deep objects visible through the whole troposphere. Respective maps of geopotential height and wind speed in the $850 \mathrm{hPa}$ are shown in Fig. 13, where the low-pressure systems are also visible to the north-northwest of Syowa Station. These systems are nearly stationary or moving slowly towards the east. A ridge of higher pressure can be seen extending from NE to SW to the southeast of the station in the $300 \mathrm{hPa}$ level. Wind speeds above Syowa Station range from 15 to $35 \mathrm{~m} \mathrm{~s}^{-1}$ at the $300 \mathrm{hPa}$ level. The wind has westward or southwestward direction over Syowa Station, along the coastline. This wind direction is visible through most of the troposphere as also seen in Fig. 13. Here a layer with enhanced wind speeds $\left(15-40 \mathrm{~m} \mathrm{~s}^{-1}\right)$ around and northwest from Syowa Station can be seen in lower altitudes. This position and wind direction would suggest the probability of the low level winds being downslope towards the coast and Syowa station, which brings up a possibility of the presence of topographically forced gravity waves. Properties of the IGWs observed during these periods are summarised in the second part of Table 1. In all the cases the length of the episodes was 1 to 5 days. The averages of the vertical wavelength (1.9 to $2.8 \mathrm{~km}$ ), the parameter $f / \hat{\omega}$ (in the range of 0.42 to 0.52$)$ and the horizontal wavelength $(180-255 \mathrm{~km})$ were in all cases higher than the respected seasonal average.
Also during all these periods the percentage of the detected downward propagating waves was much lower than the seasonal averages (ranging from 1 to $8 \%$ ). This suggests that the tropospheric disturbances are not a source of downward propagating IGWs at these heights. The saturation ratio was also higher than the respective seasonal averages thus suggesting the waves interacted with the background wind to a higher degree during these periods. The dominant horizontal propagation direction was northward or northeastward in four of the cases (Cases B, D, E, F), southward in Case A and had a dipole structure with northward and southward direction being dominant in Case C. This could be a sign of the dependence of the propagation direction on the exact position of the IGWs source relative to Syowa Station and thus could also partially explain the lack of a clear cycle of horizontal propagation directions during the year.

\section{Discussion}

The present study shows that in the altitude range of 10$12 \mathrm{~km}$, frequent periods of stronger wave activity are observed. These exhibit similar tendencies to properties of IGWs in the chosen and studied Cases A to F. During the case selection process the only condition on the properties of IGWs was that on the magnitude of horizontal perturbation variance. Other properties were thus not influenced by the selection process which would suggest that the similarity is due to similar nature of the observed IGWs. The sources of strong wave activity periods lasting on average a few days (1 to 5 days in our cases) seem to be synoptic-scale disturbances (as cut-off low-pressure systems or blocking) with high lower level wind speeds in the troposphere around Syowa Station. These disturbances exhibit similar properties during the max- 

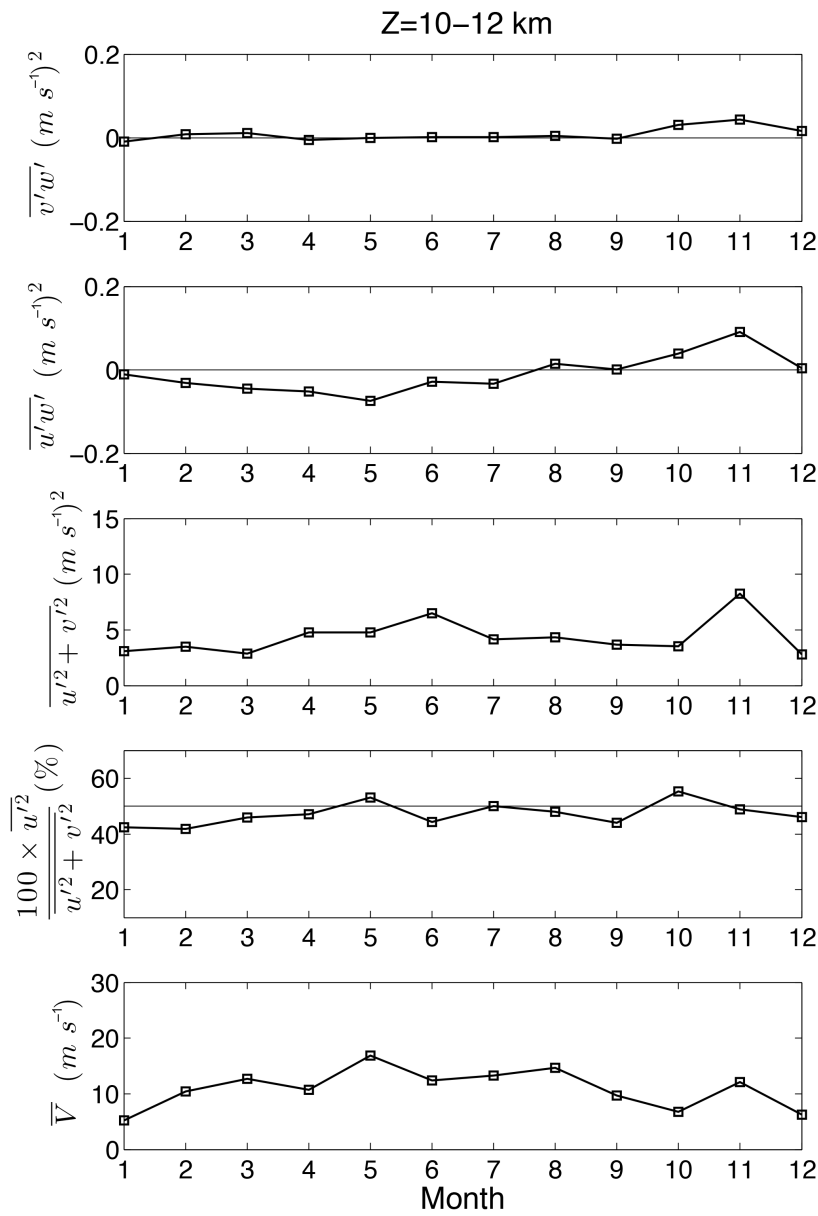

Figure 10. Monthly means of meridional $\overline{v^{\prime} w^{\prime}}$ and zonal $\overline{u^{\prime} w^{\prime}}$ components of the vertical momentum flux associated with IGWs, variance of horizontal perturbation velocities of IGWs $\overline{u^{\prime 2}+v^{\prime 2}}$ and contribution of the zonal perturbation velocity to the variances . In the last panel mean background wind $\bar{V}$ between 10 and $12 \mathrm{~km}$ is shown.

imum of horizontal perturbation variance which is a dipole like structure with deep low-pressure system (negative relative vorticity) area north-northwest of Syowa Station and an upper ridge of high-pressure, positive relative vorticity area moving over or south - southeast from the Syowa Station in the upper troposphere. Wind direction in the vicinity of Syowa Station being westward-southwestward through a significant part of the troposphere and the presence of high low-level wind speeds $\left(15-40 \mathrm{~m} \mathrm{~s}^{-1}\right)$ also suggests a possibility of the presence of topographically forced gravity waves advected by mean wind flow. These situations seem to be similar to cases studied by Yoshiki et al. (2004), who found that the gravity wave energy in the altitude range between 13 and $15 \mathrm{~km}$ is enhanced near the ridge in the upper troposphere which is connected to tropospheric vorticities, and Shibuya et al. (2015). In addition, the validity of the obtained wave parameters represented in Table 2 by the ratio $\left|\boldsymbol{k}_{\mathrm{h}} / m\right|$

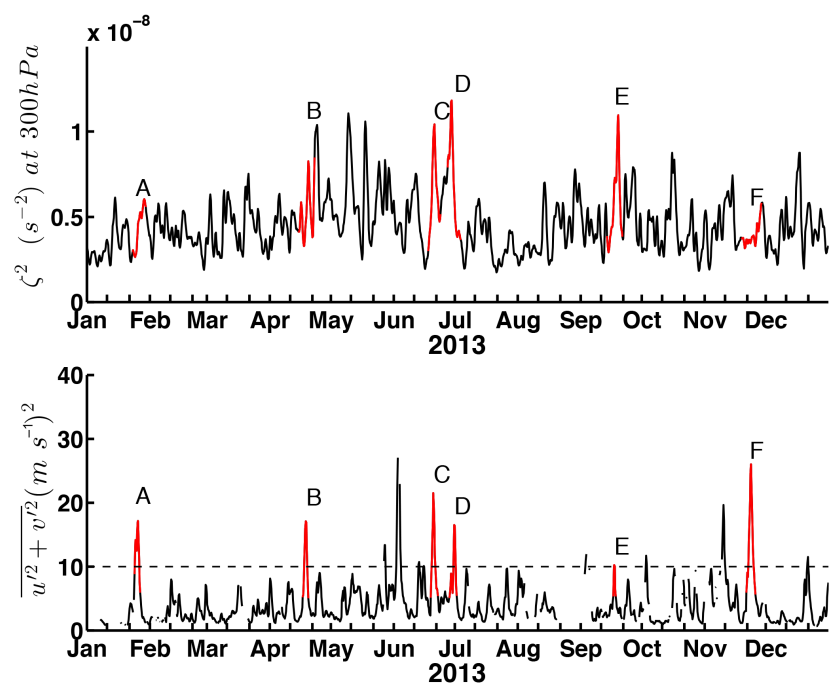

Figure 11. Change of squared relative vorticity (average for an area around Syowa Station) with the time (upper panel) and change of horizontal perturbation variance with the time (lower panel). Periods of further studied Cases A to F are denoted by the red colour. On the time axis each month is represented by three ticks, the first two representing 10 days and the last one the reminder of the month.

was also checked using the continuity equation and calculating the ratio of the vertical and horizontal wind perturbation amplitudes $\left|w_{\mathrm{f}}^{\prime} / u_{\mathrm{p}}^{\prime}\right|$. As seen in Table 2 we obtained a good match for both summer and winter seasons with a difference of up to around $20 \%$. Monthly means of the meridional component $\left(\overline{v^{\prime} w^{\prime}}\right)$ of vertical momentum flux (Fig. 10) does not show variability during the year with values close to zero or slightly positive. The zonal component $\left(\overline{u^{\prime} w^{\prime}}\right)$ of vertical momentum flux (Fig. 10) shows a cycle with negative values (down to $-0.09 \mathrm{~m}^{2} \mathrm{~s}^{-2}$ ) from February to July 2013 and close to zero or positive values (up to $0.1 \mathrm{~m}^{2} \mathrm{~s}^{-2}$ ) for the rest of the year. The vertical momentum flux at Syowa Station is thus found to be stronger than the one observed in similar altitudes in midlatitudes where in the summer $\overline{u^{\prime} w^{\prime}}$ is close to zero and in the winter time around $0.04 \mathrm{~m}^{2-2}$ (Sato, 1994). In the lowermost stratosphere, height range of $10-12 \mathrm{~km}$, the monthly means of the momentum flux and horizontal perturbation velocity variance seem to be influenced strongly by the individual, short (lasting a few days) episodes of strong wave activity. The intermittent character of the wave activity can be seen in the more detailed time series of $\overline{u^{\prime 2}+v^{\prime 2}}$ (Fig. 11) which exhibits high variability with frequent episodes lasting 1 to 6 days of higher wave activity of various magnitude. Cases of episodes with the strong wave activity (large $\overline{u^{\prime 2}+v^{\prime 2}}$ ) exhibit similar properties of IGWs observed during these times (Table 1). These suggest the similar nature of the waves and probably the same generation process. The episodes can be linked to the synoptic scale tropospheric disturbances of similar character. This is in agree- 

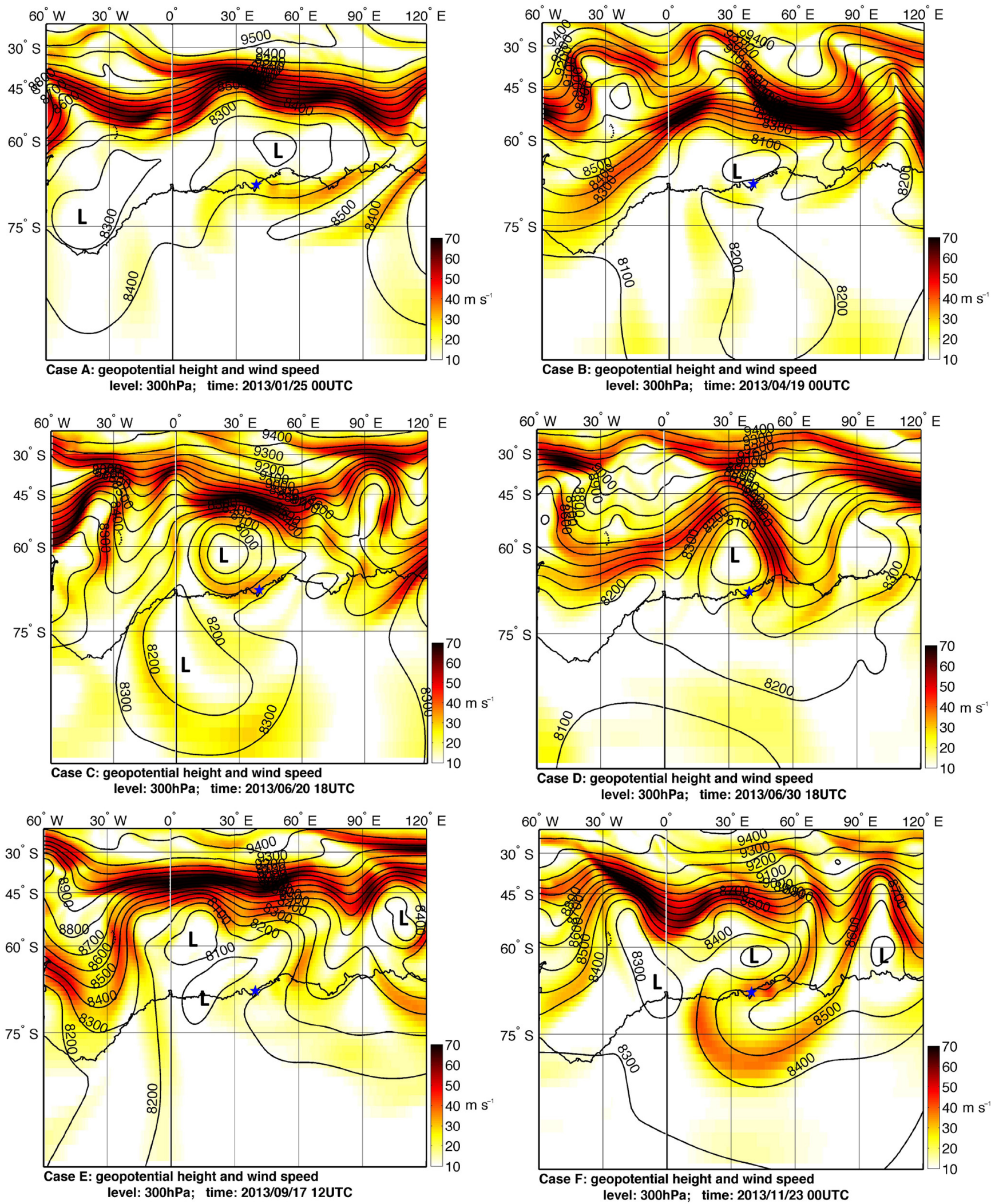

Figure 12. ERA Interim geopotential height $(10 \mathrm{gpm})$ and wind speed $\left(\mathrm{m} \mathrm{s}^{-1}\right)$ at $300 \mathrm{hPa}$ level for the six cases at the time close to maximum observed horizontal perturbation variance. Position of Syowa Station is denoted by the blue star. 

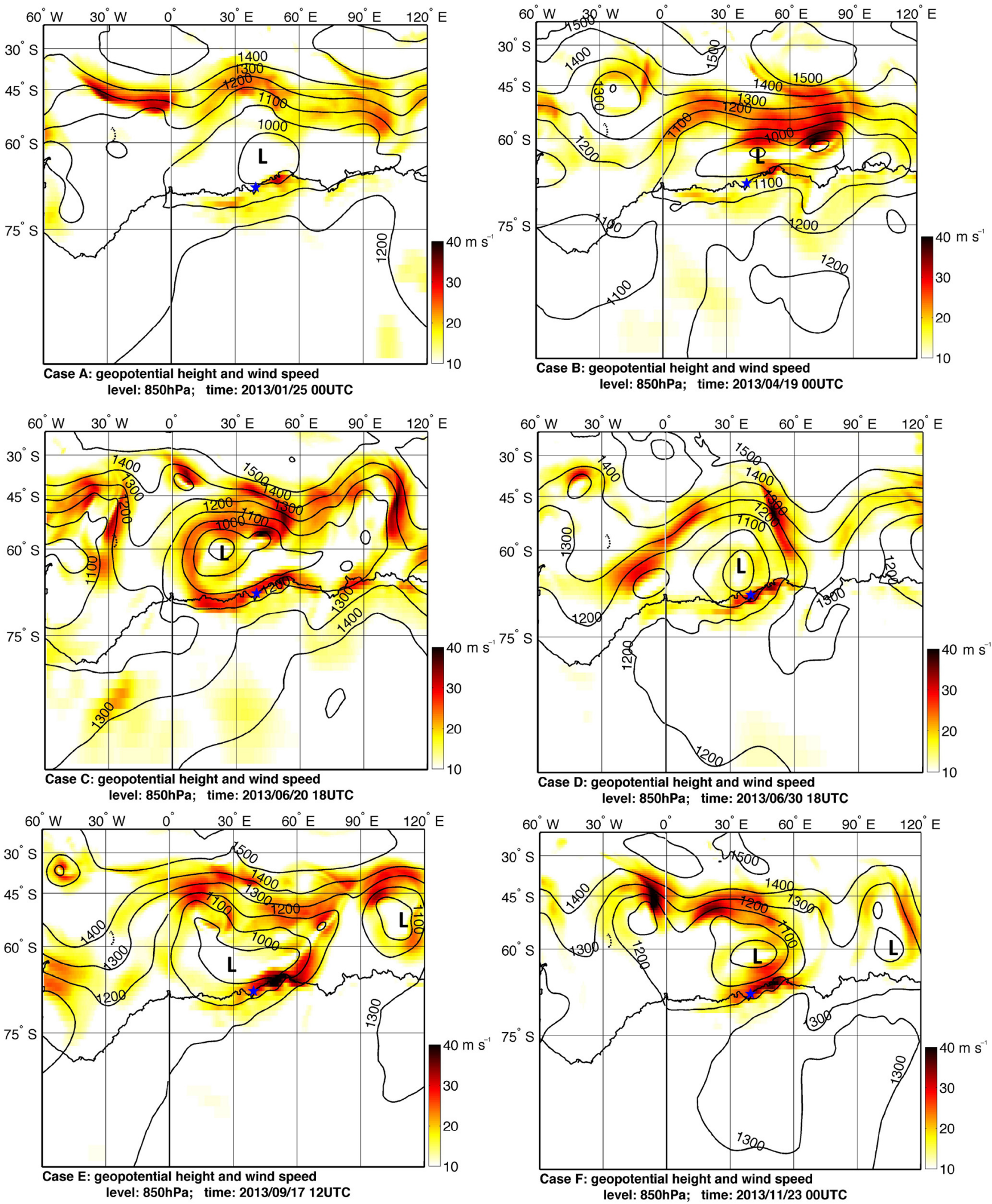

Figure 13. ERA Interim geopotential height $(10 \mathrm{gpm})$ and wind speed $\left(\mathrm{m} \mathrm{s}^{-1}\right)$ at $850 \mathrm{hPa}$ level for the six cases at the time close to maximum observed horizontal perturbation variance. Position of Syowa Station is denoted by the blue star. 
ment with the previous study by Yoshiki et al. (2004) which suggests a significant tropospheric source influence for the slightly higher altitude range of $13-15 \mathrm{~km}$.

\section{Conclusions}

One year (January to December 2013) of PANSY MST/IS radar data was analysed for properties of IGWs in the altitude region of 10 to $12 \mathrm{~km}$. A pronounced yearly cycle of IGW properties was not found. The most apparent change through the year shows the intrinsic frequency $\hat{\omega}$ was found to be lower in the summer months (January to March and December 2013) and higher in the winter months (April to November 2013). This fact also corresponds to the, on average, shorter horizontal wavelengths in the winter. Dominant horizontal propagation direction through the year changes irregularly and does not show much difference between the seasons with the slightly dominant north-northeastward propagation directions $(33 \%)$. There is a difference in the properties of IGWs between the upward and downward energy propagating waves. On average downward propagating waves show higher intrinsic frequencies, shorter horizontal wavelengths and slightly dominant southward to westward horizontal propagation directions. Important is the higher observed rate of downward propagating waves in the winter season $(18.4 \%)$ which is much higher than the rates found in the midlatitudes (Sato, 1994) and in accordance with radiosonde-based studies in the Antarctic (e.g. Yoshiki and Sato, 2000; Moffat-Griffin et al., 2011; Murphy et al., 2014). The validity of obtained wave parameters was checked by using continuity equation, and a good match was obtained for both seasons. It is found that in the lowermost stratosphere, height range of $10-12 \mathrm{~km}$, cases of episodes with the strong wave activity exhibit similar properties of IGWs. This suggests a similar nature of the waves and probably the same generation process. The episodes can be linked to the synoptic-scale tropospheric disturbances of similar character. This is in agreement with the previous study by Yoshiki et al. (2004). However, an important part in the observed momentum flux and strong wave activity can also be played by the coexistence of orographically forced gravity waves generated by strong downslope winds at the Antarctic coastline. For a determination of the relative importance of these two sources, further detailed studies are necessary. When interpreting the results of the analysis we have to keep in mind that the quality of the used observational radar data depends on the PANSY radar performance and on the atmospheric conditions. The data are usually more complete during the strong wave activity episodes, which are more favourable for radar observations. This enables better characterisation of these episodes but also might give a bias towards these values of IGW properties in the statistical overview. This limitation will be overcome soon because the full system operation of the PANSY radar commenced in March 2015. As only 1 year of data were so far analysed the observed year cycle or lack of it might only be the case for the given year. Further analysis is required to construct sound climatological overview of the properties during the year.

\section{Data availability}

The PANSY radar data are described in Sato et al. (2014) and are partly available on the PANSY project web page (http://pansy.eps.s.u-tokyo.ac.jp). Original data used in this paper are also available by request, Contact Prof. Kaoru Sato (kaoru@eps.s.u-tokyo.ac.jp) for details. The ERAInterim data are available at the ECMWF webpage: http://apps.ecmwf.int/datasets/data/interim-full-daily/ levtype $=\mathrm{sfc} /$. The radiosonde data from Syowa station are available from Japanese Meteorological Agency (JMA): http://www.data.jma.go.jp/obd/stats/etrn/upper/index.php? year $=2013 \&$ month $=\&$ day $=\&$ hour $=\&$ atm $=\&$ point $=89532$.

Acknowledgements. PANSY is a multi-institutional project with a core of the University of Tokyo and National Institute of Polar Research. This work was supported by JSPS KAKENHI Grant Numbers 25-03734, 25247075. ERA-Interim data provided courtesy of ECMWF and sonde data provided courtesy of JMA.

The topical editor, C. Jacobi, thanks Y. Murayama and one anonymous referee for help in evaluating this paper.

\section{References}

Alexander, M. J., Geller, M., McLandress, C., Polavarapu, S., Preusse, P., Sassi, F., Sato, K., Eckermann, S., Ern, M., Hertzog, A., Kawatani, Y., Pulido, M., Shaw, T. A., Sigmond, M., Vincent, R., and Watanabe, S.: Recent developments in gravity-wave effects in climate models and the global distribution of gravitywave momentum flux from observations and models, Q. J. Roy. Meteoro. Soc., 136, 1103-1124, doi:10.1002/qj.637, 2010.

Allen, S. J. and Vincent, R. A.: Gravity wave activity in the lower atmosphere: Seasonal and latitudinal variations, J. Geophys. Res., 100, 1327-1350, doi:10.1029/94JD02688, 1995.

Chagnon, J. M. and Gray, S. L.: Analysis of convectivelygenerated gravity waves in mesoscale model simulations and wind-profiler observations, Q. J. Roy. Meteoro. Soc., 134, 663676, doi:10.1002/qj.239, 2008.

ECMWF: The ERAInterim data, available at: http://apps.ecmwf.int/ datasets/data/interim-full-daily/levtype $=$ sfc/, last access: 9 May 2016.

Fritts, D. C. and Alexander, M. J.: Gravity wave dynamics and effects in the middle atmosphere, Rev. Geophys., 41, 1003, doi:10.1029/2001RG000106, 2003.

Geller, M. A., Alexander, M. J., Love, P. T., Bacmeister, J., Ern, M., Hertzog, A., Manzini, E., Preusse, P., Sato, K., Scaife, A. A., and Zhou, T.: A Comparison between Gravity Wave Momentum Fluxes in Observations and Climate Models, J. Climate, 26, 6383-6405, doi:10.1175/JCLI-D-12-00545.1, 2013.

Hertzog, A., Boccara, G., Vincent, R. A., Vial, F., and Cocquerez, P.: Estimation of Gravity Wave Momentum Flux and Phase Speeds from Quasi-Lagrangian Stratospheric Balloon Flights. Part II: 
Results from the Vorcore Campaign in Antarctica, J. Atmos. Sci., 65, 3056-3070, doi:10.1175/2008JAS2710.1, 2008.

Japanese Meteorological Agency: Radiosonde data from Syowa station, available at: http://www.data.jma.go.jp/obd/stats/etrn/ upper/index.php?year $=2013 \&$ month $=\&$ day $=\&$ hour $=\&$ atm $=$ \&point $=89532$, last access: 9 May 2016.

Jiang, J. H.: Upper Atmosphere Research Satellite (UARS) MLS observation of mountain waves over the Andes, J. Geophys. Res., 107, 8273, doi:10.1029/2002JD002091, 2002.

Lindzen, R. S.: Turbulence and stress owing to gravity wave and tidal breakdown, J. Geophys. Res., 86, 9707, doi:10.1029/JC086iC10p09707, 1981.

McLandress, C., Alexander, M. J., and Wu, D. L.: Microwave Limb Sounder observations of gravity waves in the stratosphere: A climatology and interpretation, J. Geophys. Res., 105, 1194711967, doi:10.1029/2000JD900097, 2000.

McLandress, C., Shepherd, T. G., Polavarapu, S., and Beagley, S. R.: Is Missing Orographic Gravity Wave Drag near $60^{\circ} \mathrm{S}$ the Cause of the Stratospheric Zonal Wind Biases in ChemistryClimate Models?, J. Atmos. Sci., 69, 802-818, doi:10.1175/JASD-11-0159.1, 2012.

Moffat-Griffin, T., Hibbins, R. E., Jarvis, M. J., and Colwell, S. R.: Seasonal variations of gravity wave activity in the lower stratosphere over an Antarctic Peninsula station, J. Geophys. Res., 116, D14111, doi:10.1029/2010JD015349, 2011.

Moffat-Griffin, T., Jarvis, M. J., Colwell, S. R., Kavanagh, A. J., Manney, G. L., and Daffer, W. H.: Seasonal variations in lower stratospheric gravity wave energy above the Falkland Islands: GRAVITY WAVE ENERGY ABOVE THE FALKLANDS, J. Geophys. Res.-Atmos., 118, 10861-10869, doi:10.1002/jgrd.50859, 2013.

Murphy, D. J., Alexander, S. P., Klekociuk, A. R., Love, P. T., and Vincent, R. A.: Radiosonde observations of gravity waves in the lower stratosphere over Davis, Antarctica: MURPHY ET AL., J. Geophys. Res.-Atmos., 119, 11973-11996, doi:10.1002/2014JD022448, 2014.

PANSY: PANSY radar data, available at: http://pansy.eps.s.u-tokyo. ac.jp, last access: 9 May 2016.

Sato, K.: A statistical study of the structure, saturation and sources of inertio-gravity waves in the lower stratosphere observed with the MU radar, J. Atmos.Terr. Phys., 56, 755-774, doi:10.1016/0021-9169(94)90131-7, 1994.

Sato, K. and Yoshiki, M.: Gravity Wave Generation around the Polar Vortex in the Stratosphere Revealed by 3-Hourly Radiosonde Observations at Syowa Station, J. Atmos. Sci., 65, 3719-3735, doi:10.1175/2008JAS2539.1, 2008.
Sato, K., Watanabe, S., Kawatani, Y., Tomikawa, Y., Miyazaki, K., and Takahashi, M.: On the origins of mesospheric gravity waves, Geophys. Res. Lett., 36, doi:10.1029/2009GL039908, 2009.

Sato, K., Tateno, S., Watanabe, S., and Kawatani, Y.: Gravity Wave Characteristics in the Southern Hemisphere Revealed by a High-Resolution Middle-Atmosphere General Circulation Model, J. Atmos. Sci., 69, 1378-1396, doi:10.1175/JAS-D-110101.1, 2012.

Sato, K., Tsutsumi, M., Sato, T., Nakamura, T., Saito, A., Tomikawa, Y., Nishimura, K., Kohma, M., Yamagishi, H., and Yamanouchi, T.: Program of the Antarctic Syowa MST/IS radar (PANSY), J. Atmos. Sol.-Terr. Phy., 118, 2-15, doi:10.1016/j.jastp.2013.08.022, 2014.

Shibuya, R., Sato, K., Tomikawa, Y., Tsutsumi, M., and Sato, T.: A Study of Multiple Tropopause Structures Caused by InertiaGravity Waves in the Antarctic, J. Atmos. Sci., 72, 2109-2130, doi:10.1175/JAS-D-14-0228.1, 2015.

Smith, S. A., Fritts, D. C., and Vanzandt, T. E.: Evidence for a Saturated Spectrum of Atmospheric Gravity Waves, J. Atmos. Sci., 44, 1404-1410, doi:10.1175/15200469(1987)044<1404:EFASSO>2.0.CO;2, 1987.

Vaughan, G. and Worthington, R. M.: Inertia-gravity waves observed by the UK MST radar, Q. J. Roy. Meteor. Soc., 133, 179188, doi:10.1002/qj.142, 2007.

Vincent, R. and Reid, I.: HF Doppler measurements of mesospheric gravity wave momentum fluxes, J. Atmos. Sci., 40, 1321-1333, 1983.

$\mathrm{Wu}$, D. L.: MLS observations of atmospheric gravity waves over Antarctica, J. Geophys. Res., 107, 4773, doi:10.1029/2002JD002390, 2002.

Wu, D. L.: Mesoscale gravity wave variances from AMSU-A radiances, Geophys. Res. Lett., 31, L12114, doi:10.1029/2004GL019562, 2004.

Yoshiki, M. and Sato, K.: A statistical study of gravity waves in the polar regions based on operational radiosonde data, J. Geophys. Res., 105, 17995-18011, doi:10.1029/2000JD900204, 2000.

Yoshiki, M., Kizu, N., and Sato, K.: Energy enhancements of gravity waves in the Antarctic lower stratosphere associated with variations in the polar vortex and tropospheric disturbances: GRAVITY WAVES IN THE ANTARCTIC, J. Geophys. Res.Atmos., 109, D23104, doi:10.1029/2004JD004870, 2004. 